Pontecorvo, G., Roper, J. A. \& Forbes, E. (1953). J. gen. Microbiol. 8, 198-210.

\title{
Genetic Recombination without Sexual Reproduction in Aspergillus niger
}

\author{
By G. PONTECORVO, J. A. ROPER AND E. FORBES \\ Department of Genetics, The University, Glasgow
}

\begin{abstract}
SUMMARY: Roper's technique for the production in filamentous fungi of strains with heterozygous diploid nuclei in their hyphae (Roper, 1952) has been applied successfully to Aspergillus niger, in which a sexual cycle does not occur. The diploids, heterozygous for known markers, give origin to new strains, most still diploid, homozygous for some or all of the markers and therefore associating or recombining in all possible ways the properties of the two strains from which the diploid was formed. Genetic recombination has thus been achieved in a filamentous fungus without a normal sexual cycle. Imperfect fungi are now open to genetic investigation. Deliberate 'breeding' of strains has become a practical proposition in industrial fermentations based on these fungi.
\end{abstract}

A technique developed by Roper (1952) made it possible to produce in the homothallic Aspergillus nidulans strains carrying in their hyphae and uninucleate conidia diploid nuclei heterozygous for known genetic markers. These diploid strains remained diploid through vegetative reproduction (hyphae and conidia) but yielded regularly, as a consequence of mitotic segregation and recombination, new strains homozygous for one or more of the markers (Pontecorvo \& Roper, 1952 $a, b$ ). The genetics of $A$. nidulans, which has a normal sexual stage in the life cycle, has been worked out in considerable detail (Pontecorvo, 1952b), and it was therefore possible in that species to study mitotic recombination in the light of this knowledge (Pontecorvo \& Roper, 1952 $b$; Pontecorvo, 1952b). However, Pontecorvo \& Roper (1952 a) suggested that the synthesis of diploid strains and the use of mitotic recombination would make it possible to carry out both genetic analysis, of a novel but perfectly valid type, and deliberate 'breeding' in species without a sexual stage. The first attempt in this direction, with $A$. niger, was successful (Pontecorvo, 1952a). The present paper reports details of the preliminary work done by Pontecorvo and additional results obtained since.

\section{The production of heterozygous diploid strains}

Unless explicitly stated, the techniques used in the present work were the same as those used as a routine in the extensive work with $A$. nidulans (Pontecorvo, 1952b).

Strains. Two strains, kindly supplied by Mr J. L. Yuill, were used throughout. They were both isolated by Mr Yuill after ultraviolet treatment of A. niger 680, a strain which he had isolated from Indian tea: $680 \mathrm{~A}$, mutant with split heads, as typical of the wild type, and fawn-coloured conidia; $680 \mathrm{~F}$, mutant with globose heads and yellow coloured conidia, turning dark olive on ageing. 
Both mutants were like $A$. niger 680 ('wild type') in nutritional requirements, i.e. they grew well on Czapek-Dox or similar media. Strains with these nutritional properties will be referred to as 'prototrophs'.

Media. Complete Medium (CM): a complex peptone, yeast extract, casein medium as used for $A$. nidulans. Minimal Medium (MM): a glucose, nitrate, inorganic salts medium as used for $A$. nidulans. Both strains grew well on these media. Incubation was at $28^{\circ} ; 48 \mathrm{hr}$. after plating the colonies are classifiable as to colours of conidia.

Isolation of nutritional mutants. Conidial suspensions in saline-Calzolene were well broken up and adjusted by dilution to a density of 10,000 or $5000 / \mathrm{ml}$; $\mathbf{0 . 1} \mathbf{~ m l}$. of suspension was spread on the surface of each of a number of $\mathbf{C M}$ dishes and exposed for $6 \mathrm{~min}$. with the lids removed to ultraviolet from Hanovia XI low-pressure mercury lamp at $30 \mathrm{~cm}$. distance. After incubation a random sample of about 200 well-separated colonies was isolated and the 200 strains were passed through the routine tests for identifying and characterizing nutritional mutants (Pontecorvo, $1952 b$ ). The results of one series from each of the two strains are shown on Table 1.

Table 1. Ultraviolet irradiation of strains $680 \mathrm{~A}$ ( fawn) and $680 \mathrm{~F}$ (olive) to obtain nutritional mutants

\begin{tabular}{|c|c|c|c|c|c|c|}
\hline \multirow[b]{3}{*}{ Strain } & \multicolumn{4}{|c|}{ Colonies developed } & \multirow{3}{*}{$\begin{array}{l}\text { No. of } \\
\text { colonies } \\
\text { isolated }\end{array}$} & \multirow{3}{*}{$\begin{array}{l}\text { No. of nutritional } \\
\text { mutants from isolates }\end{array}$} \\
\hline & Conidia & plated & & $\underbrace{}_{\% \text { plated }}$ & & \\
\hline & Total no. & No./dish & No. & conidia & & \\
\hline $0 \mathrm{~A}$ (fawn) & 8000 & 1000 & 587 & $7 \cdot 3$ & 197 & 3 \\
\hline $80 \mathrm{~F}$ (olive) & 4500 & 500 & 668 & $14 \cdot 8$ & 200 & 2 \\
\hline
\end{tabular}

The lower survival, after irradiation, of conidia of $680 \mathrm{~A}$ is probably due to their visibly thinner cuticle.

The five nutritional mutants were given the symbol $\mathbf{A}$ or $\mathbf{F}$, according to the parent strain from which they derived, followed by a code number. Besides having the morphological characters of the parents, i.e. fawn conidiasplit heads, or olive conidia-globose heads, respectively, the new mutants had the following nutritional properties:

A 1: requiring thiamine or its 'thiazole'; forming compact colonies with somewhat reduced growth rate.

A33: requiring arginine. Citrulline, ornithine and proline ineffective. Competitively inhibited by lysine.

A 35: requiring guanylic acid, guanosine or guanine. Adenosine and adenine very slightly effective.

F 92: requiring histidine.

F 104: requiring casein digest. Casein hydrolysate ineffective.

These five strains were purified by single colony isolation.

Formation of balanced heterokaryons. Heterokaryotic heads, of colours differing from those of the strains used and approaching that of the wild type, are known to arise in $\boldsymbol{A}$. niger when pairs of mutant strains, differing from one another and from the wild type in the colour of the conidia, are grown in 
mixed culture (Gossop, Yuill \& Yuill, 1940). Mixed cultures of the prototrophs $680 \mathrm{~A}$ (fawn) and $680 \mathrm{~F}$ (olive) confirmed this finding. A few heterokaryotic heads ranging in colour from slightly darker than those of either parent strain to as black as those of the wild type were regularly found. The chains of conidia in individual heterokaryotic heads were uniform in colour. From the fact that the chains of conidia in heterokaryotic heads were not of either parental colour, and that those in one head tended to be uniformly different from both parental types, we deduced (Pontecorvo, 1947) that the reactions blocked in the mutants involved diffusible substances. This is quite different from the situation in the white and yellow mutants of $A$. nidulans, where the reactions are cell localized (Pontecorvo, 1952b).

The production of further mutational differences mentioned in the preceding section made it possible to synthesize 'balanced' heterokaryons (Pontecorvo, 1947) differing from the component strains not only in colour and morphology of the conidial heads but also in nutritional requirements: i.e. able to grow on MM on which the component strains cannot grow singly.

The following balanced heterokaryons were synthesized in the usual way (Pontecorvo, 1952b) and kept by hyphal tip transfers on MM: A1 (fawn, thiamineless) + F92 (olive, histidineless); A35 (fawn, guanosineless) + F92 (olive, histidineless); A33 (fawn, arginineless) + F 104 (olive, requiring casein digest).

A majority of the heads of these heterokaryons grown balanced on MM were heterokaryotic and ranged in colour and morphology from wild type (black, split) to the types of the two component strains (Pl. 1, fig. 1).

Macroscopically, a balanced heterokaryotic colony shows a uniform growth on MM with peppery colour due to the thorough mixture of black, intermediate, fawn and olive heads. That the heads differing in colour and morphology from those of either component strain were actually heterokaryotic, was shown by the fact that individual conidia from them would give rise only to colonies of either component type, although conidia of both kinds were produced by one and the same head. It must be remembered that the conidia of $A$. niger are uninucleate (Yuill, 1950).

Isolation of diploids. Both techniques described by Roper (1952) were used, i.e.:

(1) Plating of conidia of balanced heterokaryons on to MM. On MM the conidia of each parental type cannot give origin to colonies because they require either of two growth factors. Diploid conidia originated from fusion of two unlike nuclei, on the other hand, being heterozygous and therefore presumably non-requirer, should grow and presumably give origin to darkspored colonies.

(2) Allowing the heterokaryon to grow on MM and searching for sectors or spots showing exclusively black growth instead of the mixture of olive, fawn, black and intermediate. Camphor treatment of the heterokaryon was carried out as described by Roper.

Diploids were obtained from all three mentioned balanced heterokaryons: A 1 + F 92, diploids obtained from sectors, both in camphor-treated and control 
heterokaryons; A 35 + F 92, diploids obtained from plating, both from camphor treated and controls; A33 + F 104, diploids obtained from sectors, without treatment.

To distinguish them from heterokaryons these diploids will be indicated by using, above and below the fraction sign, the symbols of the two strains from which they originated.

Diploids seem to arise more easily, even without camphor treatment, in A. niger than in $A$. nidulans. In the case of A35+F92 a comparison of the frequency of heterozygous diploid conidia arising in the balanced heterokaryon with and without camphor treatment was carried out (Table 2).

Table 2. Comparison of the proportions of heterozygous diploid conidia present in heterokaryons $\mathrm{A} 35+\mathrm{F} 92$ with and without camphor treatment

$\begin{array}{lccc}\text { From a treated heterokaryon } & \begin{array}{c}\text { No. of } \\ \text { plated } \\ \text { conidia }\end{array} & \text { No. } & \begin{array}{c}\text { Per 10 } \\ \text { conidia }\end{array} \\ \text { From a control heterokaryon } & \mathbf{8 , 7 0 0 , 0 0 0} & \mathbf{8} & 46 \\ \mathbf{3 . 5}\end{array}$

* Corrected for viability, which was $40 \%$. Plating at two densities : $10^{5}$ and $10^{6}$, per dish.

Taken at their face value the results of Table 2 suggest that camphor is effective. Fluctuations between the control cultures due to the clonal distribution of diploid nuclei, however, must be enormous. For this reason, and others discussed by Pontecorvo \& Roper (1952b), it would be premature to draw conclusions. From the practical point, camphor treatment was not essential with the strains of $\boldsymbol{A}$. niger used for obtaining the diploids.

All three types of diploid kept for further work were derived from nontreated heterokaryons and purified by isolation of a single conidium by means of a micromanipulator.

Properties of diploids. The diploids differed from the heterokaryons and from the haploid parent strains in a number of ways. First, they had heads almost as black a those of the original $A$. niger 680 , instead of heads of a whole range of colours like the balanced heterokaryons (Pl. 1, fig. 1), or heads uniformly fawn or uniformly olive like either parent strains. Secondly, they could grow on minimal medium like the heterokaryon but unlike either parent strain. Thirdly, on medium supplemented with either or both of the growth factors required by the parent strains, they would continue to produce uniformly dark heads as they grew, instead of segregating out into fawn and/or olive sectors like the heterokaryon. Fourthly, they had conidia about $1 \cdot 3$ times the diameter of $A$. niger 680 (Table 5; Pl. 1, figs. $3 \& 4$ ), i.e. about double the volume. Fifthly, they would produce rare fawn or olive heads (Pl. 1, fig. 2), or small spots of heads, or sectors of these two parental colours. Similarly to the results with $A$. nidulans (Pontecorvo \& Roper, 1952 $b$; Pontecorvo, 1952a), most of the strains ('segregants') established by isolating from these fawn and olive spots were still demonstrably diploid. The properties 
of these segregants, and of those showing either or both thiamine and histidine requirement (see further), support the inference, inescapable in the case of $A$. nidulans, that they originated as a consequence of mitotic segregation and recombination, probably by a mechanism of mitotic crossing-over as demonstrated by Stern (1936) in Drosophila.

\section{Segregation and recombination}

Colour segregants. All the work on mitotic segregation was carried out on diploid A1/F92. With the diploids A35/F92 and A33/F 104 we limited ourselves to verifying that they too produced occasional fawn or olive spots.

Isolation, from colonies of A 1/F92 growing on CM, of single fawn or olive heads from each spot was carried out by hand under the dissecting microscope. Each isolate was purified by streaking and, when necessary, by further single conidium micromanipulation. At the beginning of this work cultures of A 1/F 92 used for this isolation were from stab-inocula of masses of conidia at two points in each Petri dish. Later it was found preferable to plate about 100 conidia per dish. In this case not more than one fawn, and/or one olive spot per colony was isolated; the danger of isolating more than once from one and the same 'segregant' clone was thus avoided. One or two fawn spots are usually found on the average in each colony of $5 \mathrm{~mm}$. in diameter; the olive spots are much rarer.

The purified segregants were plate-tested for nutritional requirements in the routine way (Pontecorvo, 1952b). Every one of the 115 fawn or olive segregants reported in this paper and isolated as mentioned, or isolated by means of the $\mathrm{SO}_{2}$ technique (see p. 203), required one, the other, both or neither of the two growth factors required by A1 (thiamine) and F92 (histidine), respectively. No requirement not present in either parent strain arose in any one of the fully tested $\mathbf{1 7 2 7}$ isolates (including the above 115) mentioned in the present paper.

Table 3 shows the classification of sixty-one fawn or olive segregants isolated by hand from colonies of $\mathrm{Al} / \mathrm{F} 92$. The majority were prototrophs, differing from A1/F92 in colour but not in requirements and from the original strains (A1 and F 92) in requirements but not in colours. Two segregants were like $\mathrm{A} 1$ and F92, respectively, both in colour and requirements; and one was a 'recombinant' because it had the fawn colour of $\mathrm{Al}$ and the histidine requirement of $\mathbf{F} 92$.

Far more fawn than olive segregants were isolated. This reflects both the greater ease with which fawn heads are noticed and their greater frequency in colonies of A1/F92. The incidence of segregants was estimated by plating conidia of Al/F92 and classifying the resulting colonies for colours and requirements (Table 3A). Out of 651 colonies, three were fawn prototrophs and two dark thiamineless. Plating of conidia of two dark segregants26 (7) histidineless, and 12 (16) aneurineless (Tables 4 and 5), both known to give colour segregants-gave no fawn or olive out of 656 colonies. In all, therefore, segregants for fawn constitute about one in a few hundred conidia and segregants for olive are less frequent than this. 
An accurate estimate of the frequency of segregation (as distinct from the proportion of segregant conidia) would require, of course, very careful work, including serial isolation of conidia in individual chains.

The classification of the sixty-one colour segregants selected visually (Table 3) and of the 651 colonies from plated conidia of A1/F 92 showed, as

Table 3. 'First-order' segregants from diploid Aspergillus niger:

\begin{tabular}{|c|c|c|c|c|}
\hline \multirow{3}{*}{ Prototrophs } & \multicolumn{2}{|c|}{$\frac{\text { A1 }(\text { fawn, thiamineless })}{\text { F92 (olive, histidineless })}$} & \multirow[b]{2}{*}{$\begin{array}{c}\text { Requiring } \\
\text { both }\end{array}$} & \\
\hline & $\begin{array}{l}\text { Requiring } \\
\text { thiamine }\end{array}$ & $\begin{array}{l}\text { Requiring } \\
\text { histidine }\end{array}$ & & Tot \\
\hline & \multicolumn{2}{|c|}{ A. Unselected* } & & \\
\hline 646 & 2 & 0 & $\mathbf{0}$ & 648 \\
\hline 3 & 0 & 0 & 0 & 3 \\
\hline $\mathbf{0}$ & $\mathbf{0}$ & 0 & 0 & 0 \\
\hline 649 & 2 & 0 & 0 & 651 \\
\hline
\end{tabular}

(1) For colour $\dagger$

$\begin{array}{lrrrrr}\text { Fawn } & \mathbf{5 4} & 1 & 1 & 0 & \mathbf{5 6} \\ \text { Olive } & \mathbf{4} & 0 & 1 & \mathbf{0} & \mathbf{5} \\ & \mathbf{5 8} & 1 & \mathbf{2} & 0 & \mathbf{6 1}\end{array}$

(2) For requirements

$\begin{array}{lrrrrr}\text { Dark } & 591 & 13 & 9 & 0 & 613 \\ \text { Fawn } & 4 & 9 & 0 & 0 & 13 \\ \text { Olive } & 7 & 0 & 4 & 0 & 11 \\ & 602 & 22 & 13 & 0 & 637\end{array}$

* Conidia of A 1/F92 were plated on CM, and 651 colonies were classified as to colours and requirements.

$\dagger$ Fawn and olive heads, isolated from spots in A1/F92 colonies, were purified and classified as to requirements.

¥ 'Auxotroph enrichment' by $\mathrm{SO}_{2}$ treatment. Conidia of A1/F92 pre-germinated in MM, were treated with $\mathrm{SO}_{2}$ and plated on $\mathrm{CM}$. 637 colonies were classified as to colours and requirements.

expected from the work with $A$. nidulans, that in heterozygous diploids of $A$. niger segregation occurs both for colour and nutritional markers, and the various markers also recombine. It was then necessary to investigate more extensively which types of segregants and recombinants could be obtained from A1/F92.

Nutritional segregants. The identification of colour segregants is carried out by inspection. Even though fawn or olive heads constitute perhaps only 1/1000 of the total, they stand out clearly among the mass of parental (dark) heads and they can be isolated easily by hand (Pl. 1, fig. 2). Segregants for nutritional requirements, on the other hand, cannot be identified by inspection and the problem is therefore that of selecting otherwise than visually.

A technique, in the process of being developed by Forbes (1952), has been used to this purpose. It is based on the fact that $\mathrm{SO}_{2}$ is more toxic to germinating conidia than to dormant ones. If a mixture of conidia, some prototrophs and some requiring a growth factor, is incubated in MM, almost $100 \%$ of 
the former and none of the latter germinate within $6 \mathrm{hr}$. at $37^{\circ}$. Treatment with $\mathrm{SO}_{2}$ of this pre-germinated suspension kills off preferentially the prototrophs, and therefore increases the proportion of requirers ('auxotrophs') among survivors ('auxotroph enrichment'). This technique is still far from standardized, and therefore no quantitative meaning can be attached to its

Table 4. 'Second-order' segregants from first-order segregant 26 (7), dark histidine-requiring

\begin{tabular}{|c|c|c|c|}
\hline & $\begin{array}{l}\text { Requiring } \\
\text { histidine }\end{array}$ & $\begin{array}{l}\text { Requiring } \\
\text { histidine } \\
\text { and } \\
\text { aneurine }\end{array}$ & Tota \\
\hline \multicolumn{4}{|c|}{ A. Unselected* } \\
\hline Dark & 211 & $\mathbf{0}$ & 211 \\
\hline Fawn & 0 & $\mathbf{0}$ & 0 \\
\hline \multirow[t]{2}{*}{ Olive } & $\mathbf{0}$ & 0 & $\mathbf{0}$ \\
\hline & 211 & o & 211 \\
\hline \multicolumn{4}{|c|}{ B. Selected } \\
\hline Fawn & 26 & 0 & 26 \\
\hline \multirow[t]{2}{*}{ Olive } & 1 & $\mathbf{0}$ & 1 \\
\hline & 27 & 0 & 27 \\
\hline \multicolumn{4}{|c|}{ (2) For requirements $\ddagger$} \\
\hline Dark & 139 & 1 & 140 \\
\hline Fawn & 0 & $\mathbf{0}$ & 0 \\
\hline \multirow[t]{2}{*}{ Olive } & $\mathbf{0}$ & $\mathbf{0}$ & 0 \\
\hline & 139 & 1 & 140 \\
\hline
\end{tabular}

\footnotetext{
* Conidia were plated on CM and the derived colonies classified as to colours and requirements.

$\dagger$ Single fawn or olive segregant heads were isolated from colonies obtained as in footnote above, not more than one head from each colony.

‡ 'Auxotroph enrichment' by differential centrifugation. Conidia were pre-germinated for $8 \mathrm{hr}$. in liquid MM supplemented with histidine. The suspension was then centrifuged at low speed, and the supernatant plated on CM. 139 colonies were classified as to colours and requirements and one (heavy type) was of the wanted type.
}

results (Table $3 \mathrm{~B}(2)$ ): it has led, however, to the isolation of types of segregants and recombinants which it would have been very laborious to isolate without enrichment.

The technique was applied to A1/F92 conidia. A suspension (from a 4-weeks-old stab-inoculum culture on $\mathrm{CM}$ ) of $6.6 \times 10^{5}$ conidia $/ \mathrm{ml}$. was incubated in liquid MM in a water bath at $38^{\circ}$. After $7 \mathrm{hr}$. about $90 \%$ of the conidia showed germination tubes; $8 \mathrm{ml}$. of water were added to $1 \mathrm{ml}$. of pregerminated suspension, and to this $1 \mathrm{ml}$. of $\mathrm{SO}_{2}$ solution was added. After $8 \mathrm{~min}$. at room temperature the $\mathrm{SO}_{2}$ was oxidized with $\mathrm{KMnO}_{4}$ (Forbes, 1952), and plating was carried out with $0.2 \mathrm{ml}$. 13,200 conidia/Petri dish of CM. In twenty-three Petri dishes, 802 colonies came up, i.e. about 3/1000 plated conidia. 637 colonies were isolated and tested with the results shown in Table 3B (2).

As control a sample of the original suspension was plated on fifteen 
dishes of CM, at the density of sixty-six conidia per dish. A total of 666 colonies came up (about $70 \%$ of the plated conidia) and of these 651 were isolated and tested with the results shown in Table $3 \mathrm{~A}$. Clearly the $\mathrm{SO}_{2}$ technique enriched at least tenfold the proportion of requirers.

Among the recombinants for two or more of the properties in which A1 and F92 differed certain classes were not recovered from this experiment. There were neither double-requirers (thiamine and histidine) in any colour combination nor any new colour type which could be the fawn-olive double mutant, nor olive thiamine-requiring, nor fawn histidine-requiring. The last type, however, had been already obtained among the segregants selected for colour.

Seven of the dark segregants-five requiring thiamine and two histidineobtained by auxotroph enrichment were purified by single conidium micromanipulation and plated to see whether the resulting colonies would still give origin to colour segregants. All but one [15 (16), Table 5] segregated for either or both of the colours. We shall call 'first-order' segregants those originating directly from A1/F92, 'second-order' and 'third-order' segregants those originating from 'first' or 'second-order' segregants respectively.

By isolation of a single olive head from a dark thiamineless first-order segregant [12 (16), Table 5], an olive thiamineless second-order segregant $(O V$, Table 5) was secured, a type not previously obtained.

To obtain other missing types of segregants a further auxotroph enrichment treatment was carried out on strain 26 (7) (Table 5), a first-order dark histidineless which segregated for fawn and olive. This time the enrichment was based on differential centrifugation. Conidia of $26(7)$ were incubated as for the $\mathrm{SO}_{2}$ treatment, but in MM supplemented with histidine. After $8 \mathrm{hr}$. the suspension was centrifuged at 1000 r.p.m. for 2 min. Most of the germinated conidia were in the centrifugate, while a high proportion of non-germinated ones were in the supernatant. The supernatant was plated on five dishes of CM at a density of 150 conidia per dish. 149 colonies, all dark, developed out of the estimated 750 conidia plated; of those 140 were isolated and tested (Table $4 \mathrm{~B}(2)$ ): 139 required histidine like the parent strain, but one [3 (1), Table 5] was of the wanted type, i.e. thiamine- and histidine-requiring. Control platings of conidia of 26 (7) gave only dark histidineless colonies like 26 (7) [Table 4A]. Visual isolation of twenty-six fawn and one olive segregant from 26 (7) again gave only histidineless strains (Table $4 \mathrm{~B}(1)$ ).

The second-order dark, thiamine- and histidine-requiring strain [3 (1)], obtained as just mentioned by auxotroph enrichment segregated for fawn and olive: isolation of one segregant of each colour led to the establishment of third-order segregants: a fawn, thiamine- and histidine-requiring ( $F H V$, Table 5), and a similar olive strain ( $O H V$, Table 5).

With these isolations the set of strains associating the three known colours and the four nutritional types in all possible ways was completed. The twelve different combinations obtained were those of either dark, or fawn, or olive with thiamine requirement, histidine requirement, both requirements and neither, respectively. 
Clearly, one group of recombinants was still missing: i.e. the one with both fawn and olive mutant markers. However, five and perhaps all, of the six olive segregants of Table 5, produce light olive spots with split heads instead

Table 5. Mean diameter of conidia from different haploid, diploid, and segregant strains of Aspergillus niger

$\begin{array}{ccc} & \begin{array}{c}\text { No. of } \\ \text { conidia }\end{array} & \begin{array}{c}\text { Mean } \\ \text { diameter }\end{array} \\ \text { Strain } & \text { measured } & (\mu .) \\ \text { Starting } & \text { Strains } & \end{array}$

Dark

$\begin{array}{rrr}680, \text { prototroph } & 52 & 4 \cdot 27 \\ 100 & 4 \cdot 06 \\ 100 & 4 \cdot 12 \\ 100 & 4 \cdot 14\end{array}$

$\begin{array}{lrrr} & \text { Fawn } & \\ \text { 680 A, prototroph } & 60 & 3 \cdot 70 \\ & 100 & 3 \cdot 58 \\ \text { A 1, thiamineless } & 100 & 3 \cdot 58 \\ \text { A 33, arginineless } & 100 & 3 \cdot 76 \\ \text { A 35, guanosineless } & 100 & 4 \cdot 04 \\ & & \\ \text { 680 F, prototroph } & & 64 & 4 \cdot 69 \\ & 100 & 4 \cdot 40 \\ \text { F92, histidineless } & 100 & 4 \cdot 32 \\ \text { F104, casein digestless } & 100 & 4 \cdot 22\end{array}$

\section{SYNTHESIZED DIPLOIDS}

Dark

$\begin{array}{lrr}\text { A1/F 92, prototroph } & 53 & \mathbf{5 \cdot 3 9} \\ & 100 & \mathbf{5 \cdot 2 6} \\ & 100 & \mathbf{5 \cdot 2 4} \\ & 100 & \mathbf{5 \cdot 2 8} \\ \text { A35/F 92, prototroph } & 58 & \mathbf{5 \cdot 3 1} \\ & 100 & 5 \cdot 46 \\ \text { A33/F 104, prototroph } & 100 & 5 \cdot 36\end{array}$

\begin{tabular}{|c|c|c|}
\hline Strain & $\begin{array}{c}\text { No. of } \\
\text { conidia } \\
\text { measured }\end{array}$ & $\begin{array}{c}\text { Mean } \\
\text { diameter } \\
(\mu .)\end{array}$ \\
\hline \multicolumn{3}{|c|}{ SEgREgants From A 1/F92 } \\
\hline \multicolumn{3}{|c|}{ Dark } \\
\hline 26 (17) $a$, prototroph* & 100 & $5 \cdot 62$ \\
\hline $32(8)$, thiamineless* & 100 & $4 \cdot 20$ \\
\hline $29(15 a)$, thiamineless* & 100 & $4 \cdot 16$ \\
\hline 9 (17) $b$, thiamineless* & 100 & 4.54 \\
\hline $15(16)$, thiamineless & 100 & $3 \cdot 84$ \\
\hline 12 (16), thiamineless & 100 & $4 \cdot 76$ \\
\hline 23 (7), histidineless & 100 & $5 \cdot 38$ \\
\hline 26 (7), histidineless & 100 & $5 \cdot 46$ \\
\hline $\begin{array}{l}3 \text { (1), thiamine- and } \\
\text { histidineless }\end{array}$ & 100 & $5 \cdot 10$ \\
\hline \multicolumn{3}{|l|}{ Fawn } \\
\hline \multirow[t]{2}{*}{$29(15) b$, prototroph } & 79 & $\mathbf{3 \cdot 6 5}$ \\
\hline & 100 & $3 \cdot 60$ \\
\hline II $/ 33 f$, prototroph & 100 & 4.46 \\
\hline I (1), thiamineless & 100 & $3 \cdot 32$ \\
\hline $4(2) b$, thiamineless & 100 & $3 \cdot 62$ \\
\hline \multirow[t]{2}{*}{ 6, histidineless } & 86 & $4 \cdot 00$ \\
\hline & 100 & $3 \cdot 62$ \\
\hline $\begin{array}{l}F H V \text {, thiamine- and } \\
\text { histidineless }\end{array}$ & 100 & $4 \cdot 80$ \\
\hline \multicolumn{3}{|l|}{ Olive } \\
\hline II/33, prototroph & 62 & $5 \cdot 48$ \\
\hline 29 (15) $c$, prototroph & 100 & $4 \cdot 62$ \\
\hline$O V$, thiamineless & 100 & $5 \cdot 16$ \\
\hline I/11, histidineless & 100 & $4 \cdot 42$ \\
\hline $15(5) c$, histidineless & 100 & $4 \cdot 70$ \\
\hline $\begin{array}{l}O H V \text {, thiamine- and } \\
\text { histidineless }\end{array}$ & 100 & $5 \cdot 14$ \\
\hline
\end{tabular}

No. of Mean meter SROM A 1/F 92 
would have an example of 'epistasis' similar to that found in $A$. nidulans between white, yellow and green (Pontecorvo, 1952b).

A number of genetic tests which could decide this question have already been devised, they include a thorough search for light olive second-order segregants from first-order fawn segregants; and an investigation of the colours of heterokaryotic heads produced by various combinations of light olive, fawn and olive strains.

Table 3 reveals a fact already pointed out by Pontecorvo $(1952 a)$; i.e. that the distribution of simultaneous segregations for more than one marker is not at random among segregants. In summary:

\begin{tabular}{|c|c|c|c|c|c|}
\hline \multirow[b]{2}{*}{ Colours } & \multicolumn{2}{|c|}{$\begin{array}{c}\text { Among nutritional } \\
\text { segregants }\end{array}$} & \multirow{2}{*}{$\begin{array}{c}\text { Nutritional } \\
\text { properties }\end{array}$} & \multicolumn{2}{|c|}{$\begin{array}{l}\text { Among colour } \\
\text { segregants }\end{array}$} \\
\hline & Thiamineless & Histidineless & & Fawn & Olive \\
\hline Fawn & 10 & 1 & Thiamineless & 10 & 0 \\
\hline Olive & 0 & $\mathbf{5}$ & Histidineless & 1 & $\mathbf{5}$ \\
\hline All colours & 25 & 15 & All types & 72 & 16 \\
\hline
\end{tabular}

In the present case, how much of this great excess of simultaneous segregation for more than one marker is due to linkage and how much to segregation occurring wholesale in certain nuclei will have to be investigated.

Properties of segregants. Table 5 gives the diameter of the conidia of the original strain, the mutants derived from it, the three synthesized diploids, and a sample of segregants of first, second and third order from A1/F92. There is no overlap between the diameters of the conidia of the synthesized diploids and any of the haploid strains, though there is considerable variation in the diameters of the latter, the olive strains having larger conidia than the fawn. As shown by replicates of measurements of the same strain under different conditions, the diameter of the conidia seems to be a rather constant strain character.

The synthesized diploids have diameters of conidia almost exactly 1.3 times that of $A$. niger 680 , i.e. a volume almost exactly double. On the other hand, the diameters of the segregants cover a continuous range, from that of the smallest haploid to that of the largest diploid. Clearly in $A$. niger the diameter of the conidia is not very significant for identifying diploid strains whenever a number of known and unknown genetic differences are segregating and recombining. By conidial size alone, we cannot tell which segregants are still diploid, like A1/F92 from which they derived by one or more steps, and which are haploid. Tests of further segregation, however, can give a one-way answer in some cases.

If a segregant for one of the markers, say a requirement, still segregates for one or more of the remaining markers for which A1/F92 was heterozygous, we can conclude that it is a diploid (or perhaps a higher polyploid). However, if a segregant does not segregate further, we cannot conclude that it is haploid, because it could be a diploid homozygous at all relevant loci. As segregation for colour markers is detected visually, and for requirements by laborious tests, we have limited ourselves to the former for most of the segregants of Table 5. In the case of fawn strains, no further colour segregation has been 
detected so far. In the case of olive strains, as already stated, five and perhaps all six investigated segregate for light olive: the precise nature of these light olive putative segregants will have to be established. In the case of the nine dark segregants of Table 5, eight give further colour segregation; three for fawn and olive, four for fawn only, and one for olive only. The one which does not segregate further-15(16) - incidentally, is the one with the smallest conidia.

It is certain, thus, that a high proportion of dark segregants are still diploid and the same is probably true of the olive segregants. As to the fawn, a way to detect diploidy would be a search for nutritional second-order segregants.

Genetic analysis. Mitotic segregation and recombination makes it possible to analyse genetically our strains even though the precise rules of the game are as yet unknown. Our original strains A1 and F92 differed in the following properties from one another and from the wild type:

Morphology: split heads versus globose heads, the wild type having split heads.

Colour: fawn versus olive, the wild type having dark heads.

Requirements : thiamine requirement versus histidine requirement, the wild type having neither.

We have therefore a minimum of five pairs of alternative properties: split/globose; fawn/dark; olive/dark; thiamine requirement/thiamine independence; histidine requirement/histidine independence.

All of these differences are under genetical control because the heterokaryons between A1 and F92 show properties different from those of either strain and approaching those of the wild type, but single conidia from heterokaryotic heads give origin again to unchanged A1 or F92. Furthermore, every one of these differences segregates vegetatively in the heterozygous diploids, and recombination between all but two of them has been obtained. The two which so far have not been unquestionably recombined are split/globose and olive/dark: we have not obtained globose fawn or globose dark types, globose recombinants being all olive, though light olive strains with split heads arise from most globose olive strains.

Leaving for the moment the question of whether globose and olive are recombinable differences, i.e. due to mutation at different loci, we have thus identified at least four different loci, recombination between which occurs readily. These loci may be symbolized by pairs of alleles as follows: $A / a$, normal versus fawn colour; $O / o$, normal versus olive colour; $\boldsymbol{T H} \boldsymbol{H} / \mathrm{th} i$, independence of, versus requirement for thiamine or 'thiazole'; HIST/hist, independence of, versus requirement for histidine.

Using the capital symbols for the alleles of the wild type (clearly all dominant both in the heterokaryon and the diploid) we may indicate the tentative genotypes of our starting strains and of diploid A1/F 92 as follows:

$\begin{array}{lllll}\text { A. niger 680 } & A & o & \text { THI } & \text { HIST } \\ 680 \mathrm{~A} & a & O & \text { THI } & \text { HIST } \\ 680 \mathrm{~F} & A & o & \text { THI } & \text { HIST } \\ \text { A1 } & a & o & \text { thi } & \text { HIST } \\ \text { F92 } & A & o & \text { THI } & \text { hist } \\ \text { A1/F92 } & a / A & \text { O/o } & \text { thi/THI } & \text { HIST/hist }\end{array}$


When it comes to those segregants and recombinants which are certainly still diploid (because they segregate further) we have several possible genotypes for most of the phenotypes. For instance, as to colours:

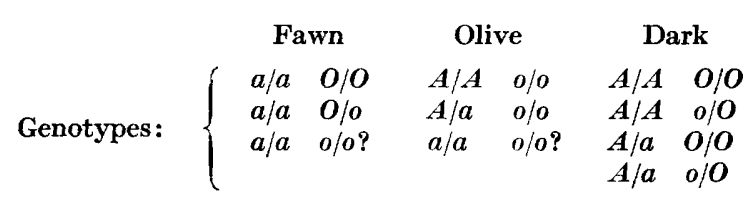

As to requirements, diploid segregants not requiring a growth factor may be of two genotypes: homozygous for the dominant allele or heterozygous. In all, therefore, there are at least $3^{4}=81$ different genotypes, but probably only 12 , or possibly 16 , distinguishable phenotypes: 12 have already been obtained.

All of the genotypes could, in theory, be distinguished by appropriate genetic tests; one kind of test is that of further segregation, which is easy enough in the case of colour markers and which we have in fact carried out on some segregants. Another test is that of finding out the kinds of phenotype produced in heterokaryons. This we have carried out in three cases, between fawn and olive segregants, obtaining dark heterokaryotic heads in two cases but not in a third.

Other important problems are, of course, those of linkage. The data of Table 3 are already suggestive of something in this direction. A serious study of linkage, however, must wait until the process of mitotic recombination is better understood. For this purpose $A$. niger is unsuitable because of the impossibility of cross-checking the results of mitotic recombination with those obtained via sexual reproduction. The work in progress with $A$. nidulans is more promising (Pontecorvo \& Roper, 1952 $b$; Pontecorvo, 1952 $a$ ). We shall be able to come back to $A$. niger as soon as the latter work has yielded some preliminary answer.

\section{Conclusions}

The present work shows that by synthesizing heterozygous diploid strains and investigating the recombinants produced mitotically by them, genetic analysis is possible in a species of filamentous fungus in which the standard sexual cycle does not occur. In the present preliminary work at least four loci have been identified on the basis of an equal number of recombinable differences. A search for linkage between any two or more of these, or of other, loci and the construction of chromosome maps is only a matter of extending the present work.

The approach described here, in addition, has very practical implications for those industrial fermentations which use filamentous fungi. By producing heterozygous diploids between two strains differing in properties, new stable strains can be obtained associating and recombining these properties or showing new ones. In the 'breeding' of improved strains of industrial moulds our methods have potentialities and limitations of the same order as those of hybridization in horticulture. 


\section{REFERENCES}

Forbes, E. (1952). The use of $\mathrm{SO}_{2}$ for selecting auxotrophs in filamentous fungi. Microbial Genetics Bull. 6, 26.

Gossop, G. H., YuILL, E. \& YurLL, J. L. (1940). Heterogeneous fructifications in Aspergillus. Trans. Brit. mycol. Soc. 24, 337.

Pontecorvo, G. (1947). Genetic systems based on heterokaryosis. Cold Spr. Harb. Sym. quant. Biol. 11, 193.

Ponteconvo, G. (1952a). Non-random distribution of multiple mitotic crossingover among nuclei of heterozygous diploid Aspergillus. Nature, Lond. 170, 204.

Ponteconvo, G. (1952b). The genetics of Aspergillus nidulans. Advanc. Genet. 5 (in the press).

Ponteconvo, G. \& Roper, J. A. (1952a). Genetic analysis without sexual reproduction by means of polyploidy in Aspergillus nidulans. J. gen. Microbiol. 6, vii.

Pontecorvo, G. \& Roper, J. A. (1952b). Diploids and mitotic recombination. Advanc. Genet. 5 (in the press).

Roper, J. A. (1952). Production of heterozygous diploids in filamentous fungi. Experientia, 8, 14.

Stern, C. (1936). Somatic crossing-over and segregation in Drosophila melanogaster. Genetics, 21, 625.

YuILL, E. (1950). The numbers of nuclei in conidia of Aspergilli. Trans. Brit. mycol. Soc. 33, 324.

\section{EXPLANATION OF PLATE}

Fig. 1. Balanced heterokaryon between strains A1 (fawn, split heads, thiamine-requiring) and F92 (olive, globose heads, histidine-requiring). Note fawn split, olive small globose, black split heads and heads of intermediate shades and shapes.

Fig. 2. Diploid A1/F92 formed from the same two strains as the heterokaryon in fig. 1. Almost all heads are black; the single fawn split head is a segregant.

Figs. 3 \& 4. Conidia of 11-day-old cultures on complete medium, $\times 500$. Fig. 3. Haploid A. niger 680. Fig. 4. Diploid A1/F92.

(Received 5 August 1952) 
Journal of General Microbiology, Vol. 8, No. 1
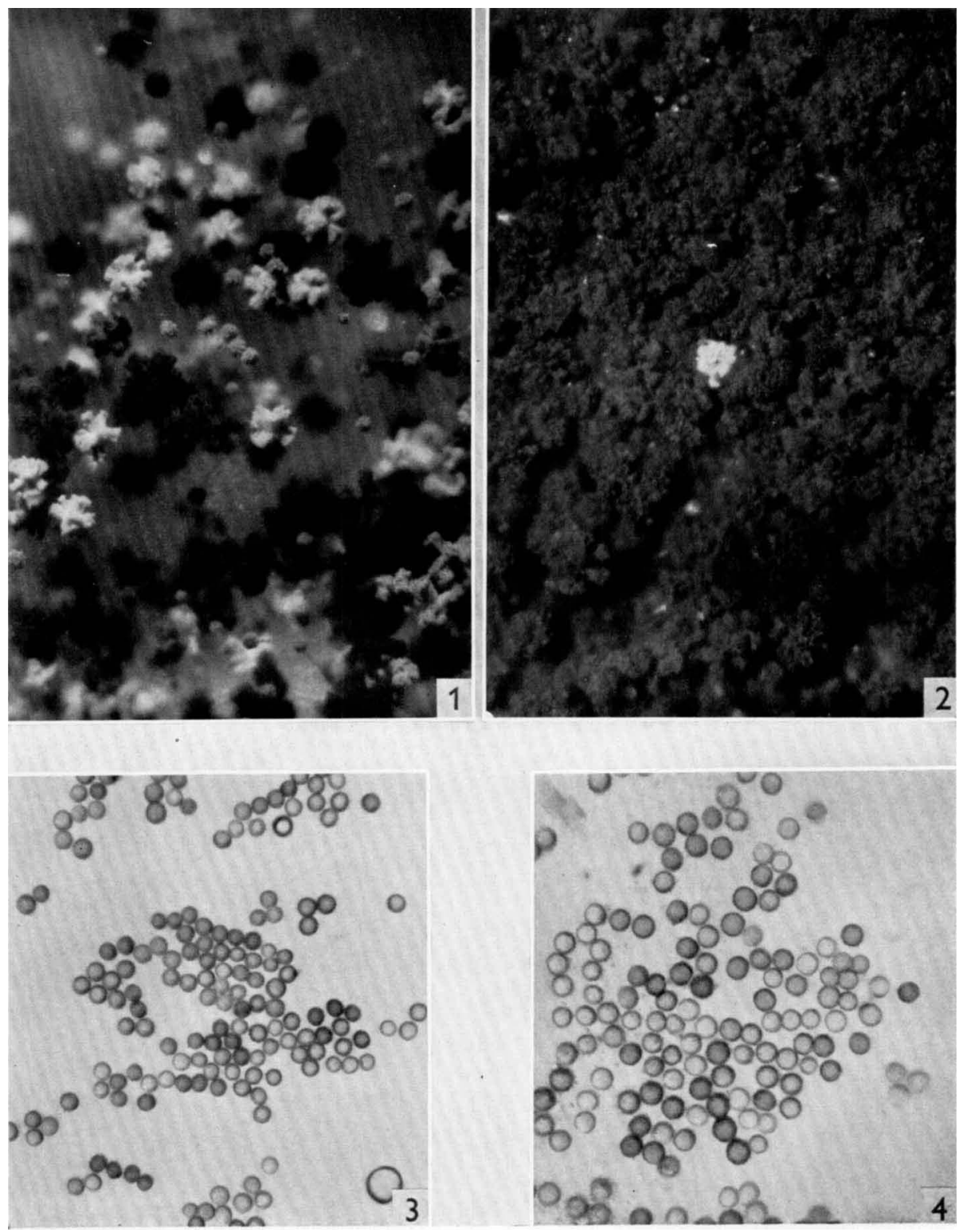

G. Pontecorvo, J. A. Roper \& E. Forbes-Genetic recombination, Plate 1 